\title{
Cough and dyspnea during bronchoconstriction: comparison of different stimuli
}

\author{
Thais R Suguikawa*1, Clecia A Garcia², Edson Z Martinez ${ }^{2}$ and \\ Elcio O Vianna ${ }^{1}$
}

Address: ${ }^{1}$ Department of Medicine, Medical School of Ribeirão Preto, University of S. Paulo at Ribeirão Preto, Brazil and ${ }^{2}$ Department of Social Medicine, Medical School of Ribeirão Preto, University of S. Paulo at Ribeirão Preto, Brazil

Email: Thais R Suguikawa* - tha_ss@yahoo.com; Clecia A Garcia - solclecia@hotmail.com; Edson Z Martinez - edson@fmrp.usp.br; Elcio O Vianna - evianna@uol.com.br

* Corresponding author

Published: 25 June 2009

Cough 2009, 5:6 doi:10.1186/1745-9974-5-6

This article is available from: http://www.coughjournal.com/content/5/I/6

(C) 2009 Suguikawa et al; licensee BioMed Central Ltd.

This is an Open Access article distributed under the terms of the Creative Commons Attribution License (http://creativecommons.org/licenses/by/2.0), which permits unrestricted use, distribution, and reproduction in any medium, provided the original work is properly cited.
Received: 22 December 2008

Accepted: 25 June 2009

\begin{abstract}
Background: Bronchial challenge tests are used to evaluate bronchial responsiveness in diagnosis and follow-up of asthmatic patients. Challenge induced cough has increasingly been recognized as a valuable diagnostic tool. Various stimuli and protocols have been employed. The aim of this study was to compare cough and dyspnea intensity induced by different stimuli.
\end{abstract}

Methods: Twenty asthmatic patients underwent challenge tests with methacholine, bradykinin and exercise. Cough was counted during challenge tests. Dyspnea was assessed by modified Borg scale and visual analogue scale. Statistical comparisons were performed by linear mixed-effects model.

Results: For cough evaluation, bradykinin was the most potent trigger $(p<0.0 \mathrm{I})$. In terms of dyspnea measured by Borg scale, there were no differences among stimuli $(p>0.05)$. By visual analogue scale, bradykinin induced more dyspnea than other stimuli $(p \leq 0.04)$.

Conclusion: Bradykinin seems to be the most suitable stimulus for bronchial challenge tests intended for measuring cough in association with bronchoconstriction.

\section{Background}

Cough is one of the most common symptoms in asthma patients, although little attention has been paid to its role in asthma diagnosis and follow-up. Some recent studies from Europe have suggested that cough provoked by inhalation challenges may be useful in diagnosing asthma $[1,2]$, and also in evaluating the response to asthma treatment [3]. These studies support the concept that cough could be utilized as a surrogate for bronchoconstriction when studying patients likely to be unable to perform spirometry. However, the relationship between intensity of coughing and level of bronchoconstriction is still a matter of debate.

Sheppard et al studied the relationship between cough and bronchoconstriction caused by inhaled distilled water aerosol in subjects with asthma. Atropine caused inhibition of the water-induced bronchoconstriction, but did not inhibit cough. Their data suggest that waterinduced bronchoconstriction involves cholinergic nerves and that water-induced cough is not dependent on bronchoconstriction[4]. On the other hand, Koskela et al 
showed that direct, indirect, and combined airway challenges are able to provoke cough, but the significance of the cough response differs considerably among the challenge stimuli[2].

Therefore, the utility of cough during bronchial challenges in diagnosing asthma may depend on the stimulus. In the present study, we hypothesized that bradykinin causes more cough and dyspnea. Bradykinin is thought to be an indirect stimulus, i.e., causes airflow limitation by an action on cells other than the effector cells (smooth muscle). Possible mechanisms by which bradykinin may cause bronchoconstriction involve the stimulation of sensory nerves to induce smooth muscle contraction via neural reflex pathways and this may contribute to cough stimulus in asthma [5]. The aim of this study was to compare cough and dyspnea intensity induced by bradykinin, methacholine, and exercise challenge.

\section{Methods}

Subjects

Asthma was defined by clinician diagnosis [6]. We recruited asthmatics with history of symptoms induced by exercise that were studied during a clinically stable period, without symptoms of upper respiratory tract infection for at least six weeks prior to the study. Exclusion criteria were: smoking, other pulmonary disease, pregnancy, use of medication other than bronchodilator or inhaled steroids, inability to perform the exercise challenge, incapacity to understand the protocol, including illiteracy. Longacting $\beta_{2}$-agonist was withheld for at least 24 hours, and short-acting $\beta_{2}$-agonist was withheld for 12 hours before evaluations. Moreover, the time interval between the last dose of bronchodilator and the challenge test was established to be the same before all tests. All subjects gave informed consent to this Institutional Review Board approved protocol.

\section{Study design}

Three challenge tests were performed on three different days, at the same time of day, at least 48 hours apart. Tests sequence was randomly determined. Subjects had their coughs counted during every challenge test and were requested to rate discomfort associated with the act of breathing one minute before every $\mathrm{FEV}_{1}$ maneuver during all challenge tests. Patients registered dyspnea intensity in a VAS and answered, according to modified Borg scale.

\section{Assessment of cough}

A cough is a reflex act with an explosive expiration. The three phases of a cough are: 1) a deep inspiration; 2) compression of air in the lungs and airways by forceful concentration of the expiratory muscles coupled with closure of the glottis and opening of the larynx; 3) sudden explosive expiration followed by narrowing of the glottis and return of the larynx to its normal inspiratory position [7]. We counted every phase 3 as one cough. This counting was performed during two minutes before spirometry (baseline evaluation) and during two minutes before every $\mathrm{FEV}_{1}$ maneuver during inhalation challenge tests. During exercise challenge test, cough was counted before and after exercise (during all recovering time). The act of clearing the throat was not considered as a cough. The same technician counted cough all over the study, in a quiet and calm environment, without performing other tasks.

\section{Assessment of perception of dyspnea}

Subject was free to interpret respiratory discomfort in any way he or she felt appropriate, and no further instructions were given. The subject rated the intensity of symptom on the modified Borg scale, a scale numbered 0 to 10 . These are tagged to descriptive phrases, describing increasing intensities of asthma sensations, and subjects were not restricted to whole numbers[8]. Visual analogue scale was an horizontal straight line $(10 \mathrm{~cm})$ labeled "no breathlessness at all" $(0 \mathrm{~cm})$ at one end and "the most extreme breathlessness ever experienced" $(10 \mathrm{~cm})$ at the other, whereby equal distances are meant to represent equal severities of breathlessness [9,10]. During tests, subjects were blinded to their lung function response and to previous dyspnea scores.

\section{Inhalation challenge tests}

Methacholine and bradykinin challenge tests were performed following the same protocol, according to a standardized tidal breathing method. For safety reasons, baseline $\mathrm{FEV}_{1} \geq 50 \%$ of predicted value was requisite to start challenge tests. Acetyl- $\beta$-methylcholine chloride (Sigma-Aldrich, Saint Louis, MO, USA) and tri-acetate of bradykinin in normal phosphate-buffered saline solution were aerosolized by a DeVilbiss 646 nebulizer (Sunrise Medical HHG Inc, Somerset, PA, USA) during tidal breathing for two minutes, driven by a computer-activated dosimeter (Koko Digidoser System, PDS Instrumentation, Inc., Louisville, CO, USA). Phosphate-buffered saline solution was inhaled first, followed by test solution in two-fold increasing concentrations (0.06 to $16 \mathrm{mg} / \mathrm{ml})$. Measurements of $\mathrm{FEV}_{1}$ were made using the Koko Spirometer before test and two minutes after every inhalation. Cough was counted during these two-minute intervals. The challenge test was discontinued if $\mathrm{FEV}_{1}$ dropped 20\% or more from baseline. The provocative concentration of methacholine or bradykinin resulting in a $20 \%$ fall in $\mathrm{FEV}_{1}\left(\mathrm{PC}_{20} \mathrm{MCh}\right.$ or $\mathrm{PC}_{20} \mathrm{BK}$, respectively) was calculated by linear interpolation of dose-response curves [11].

\section{Exercise challenge test}

After one minute of light exercise on the inclined $\left(10^{\circ}\right)$ treadmill, the speed was quickly increased to achieve $80 \%$ 
of the maximum predicted heart rate; this speed was then maintained for six minutes. Standard measurements of spirometry were obtained before, immediately after and $5,10,15,20,30$ and 45 minutes after exercise. Cough was counted before and after exercise (during all the recovering time). The maximum percentage of change from baseline was calculated as $100 \times$ the decrease in $\mathrm{FEV}_{1} /$ baseline $\mathrm{FEV}_{1}$ [12]. With the aid of air conditioning apparatus, the exercise laboratory temperature and relative humidity were kept at $20^{\circ}$ to $22^{\circ} \mathrm{C}$ and $50 \%$ to $55 \%$, respectively.

\section{Statistical analysis}

Since the response variables are assumed to be continuous, linear mixed-effects models were used to allow for dependencies between measurements on the same patient. These models were used to verify the effect of challenge tests on dyspnea (Borg and VAS) and on cough [13], considering that each patient underwent all the three different tests. We assume that these models have normally distributed residual with mean zero and constant variance. Like this, the distribution of residuals was graphically verified and when it was not compatible with this presupposition, new models were adjusted with logarithms transformation. Statistical interaction was examined by including the independent variables and their cross-product term in the model. Age, gender, atopy status, body mass index, $\mathrm{FEV}_{1}$, baseline $\mathrm{FEV}_{1}$, all stimuli (bradykinin, methacholine and exercise), baseline symptom, inhaled corticosteroid dose, tests sequence and intercept were considered as covariables. All the models are fitted by the method of maximum likelihood using the SAS software $9^{\text {th }}$ version [14].

\section{Results}

We studied 20 asthmatic outpatients (10 women; age range: 21 - 46 years). All subjects were on inhaled shortacting $\beta_{2}$-agonists as rescue medication and 14 subjects on inhaled corticosteroid therapy. Characteristics of studied subjects can be seen in Table 1 . The geometric mean $\mathrm{PC}_{20}$ $\mathrm{MCh}$ was 0.36 (range 0.08 to $2.35 \mathrm{mg} / \mathrm{ml}$ ), and the geometric mean $\mathrm{PC}_{20} \mathrm{BK}$ was 0.68 (range 0.05 to $3.87 \mathrm{mg}$ / $\mathrm{ml})$. The mean $( \pm \mathrm{SD}) \mathrm{FEV}_{1}$ fall after exercise was $20.45 \%$ $\pm 3.43 \%$.

Table 2 shows intensity of symptoms among stimuli. Cough induced by bradykinin was more intense. Bradykinin also led to more intense breathlessness detected by VAS scale, but not by Borg scale. The pairwise comparisons of challenge tests are shown in Table 3. For the cough evaluation, bradykinin caused more cough in comparison

Table I: Characteristics of the subjects studied

\begin{tabular}{|c|c|c|c|c|c|c|c|c|}
\hline Subject & Gender & $\begin{array}{l}\text { Age } \\
\text { (years) }\end{array}$ & BMI & $\begin{array}{l}\text { FEV , } \\
\text { (L) }\end{array}$ & $\begin{array}{l}\text { FEV } \\
\text { (\%) }\end{array}$ & Tests sequence & $\mathrm{PC}_{20} \mathrm{MCh}(\mathrm{mg} / \mathrm{ml})$ & $\mathrm{PC}_{20} \mathrm{BK}(\mathrm{mg} / \mathrm{ml})$ \\
\hline I & $M$ & 23 & 23.8 & 3.24 & 76 & $\mathrm{BK}, \mathrm{EIB}, \mathrm{MCh}$ & 0.83 & 2.30 \\
\hline 2 & $M$ & 23 & 24.2 & 3.56 & 83 & $\mathrm{EIB}, \mathrm{BK}, \mathrm{MCh}$ & 0.21 & 0.15 \\
\hline 3 & $M$ & 21 & 24.0 & 2.98 & 69 & $\mathrm{BK}, \mathrm{EIB}, \mathrm{MCh}$ & 0.19 & 1.16 \\
\hline 4 & $\mathrm{~F}$ & 30 & 19.1 & 3.44 & 110 & MCh, EIB, BK & 1.13 & 3.87 \\
\hline 5 & $\mathrm{~F}$ & 43 & 24.8 & 2.55 & 83 & EIB, MCh, BK & 0.56 & 0.42 \\
\hline 6 & $\mathrm{~F}$ & 23 & 25.8 & 2.26 & 68 & $\mathrm{MCh}, \mathrm{BK}, \mathrm{EIB}$ & 0.13 & 0.58 \\
\hline 7 & $\mathrm{~F}$ & 45 & 25.7 & 2.13 & 80 & $\mathrm{EIB}, \mathrm{BK}, \mathrm{MCh}$ & 0.47 & 1.62 \\
\hline 8 & $\mathrm{~F}$ & 39 & 27.9 & 1.66 & 54 & $\mathrm{MCh}, \mathrm{BK}$, EIB & 0.14 & 0.12 \\
\hline 9 & $\mathrm{~F}$ & 24 & 33.6 & 2.81 & 87 & $\mathrm{BK}, \mathrm{MCh}, \mathrm{EIB}$ & 0.16 & 1.17 \\
\hline 10 & $\mathrm{~F}$ & 38 & 31.2 & 2.56 & 88 & BK, MCh, EIB & 1.00 & 0.22 \\
\hline II & $M$ & 39 & 22.1 & 2.90 & 74 & EIB, MCh, BK & 0.62 & 0.06 \\
\hline 12 & $\mathrm{~F}$ & 24 & 32.7 & 3.16 & 91 & MCh, EIB, BK & 0.17 & 1.16 \\
\hline 13 & $M$ & 24 & 19.2 & 3.73 & 90 & $\mathrm{EIB}, \mathrm{MCh}, \mathrm{BK}$ & 0.42 & 1.48 \\
\hline 14 & $M$ & 27 & 31.8 & 3.26 & 77 & $M C h, B K$, EIB & 0.28 & 2.37 \\
\hline 15 & $M$ & 46 & 26.8 & 3.29 & 83 & $\mathrm{EIB}, \mathrm{BK}, \mathrm{MCh}$ & 0.38 & 0.71 \\
\hline 16 & $M$ & 33 & 23.1 & 3.21 & 73 & $\mathrm{BK}, \mathrm{MCh}$, EIB & 2.35 & 2.32 \\
\hline 17 & $\mathrm{~F}$ & 24 & 19.6 & 2.57 & 80 & MCh, EIB, BK & 0.95 & 3.56 \\
\hline 18 & $\mathrm{~F}$ & 26 & 21.8 & 2.30 & 80 & MCh, EIB, BK & 0.15 & 0.20 \\
\hline 19 & $M$ & 38 & 24.6 & 2.25 & 64 & $\mathrm{BK}, \mathrm{MCh}$, EIB & 0.08 & 0.05 \\
\hline 20 & $M$ & 32 & 28.7 & 3.00 & 80 & MCh, BK, EIB & 0.58 & 1.73 \\
\hline Mean & & 31 & 25.5 & 2.84 & 79.5 & & $0.36^{a}$ & $0.68^{a}$ \\
\hline SD & & 8 & 4.4 & 0.54 & 11.6 & & $2.45^{b}$ & $3.84^{b}$ \\
\hline
\end{tabular}

M: male; F: female; BMI: body mass index; $\mathrm{FEV}_{1}$ : Forced expiratory volume in one second; $\mathrm{MCh}$ : methacoline; BK: bradykinin; EIB: exercise-induced bronchospasm; $\mathrm{PC}_{20}$ : provocative concentration that results in a $20 \%$ fall in $\mathrm{FEV}_{1}$.

a geometric mean. ${ }^{b}$ geometric standard deviation. 
Table 2: Symptoms intensity during bronchoconstriction

\begin{tabular}{cccc}
\hline Stimuli & Cough (total of episodes) & Dyspnea - Borg & Dyspnea - VAS \\
Bradykinin & $72.40 \pm 69.26^{*}$ & $3.60 \pm 2.30$ & $3.26 \pm 2.47 \#$ \\
Methacholine & $18.15 \pm 20.58$ & $3.40 \pm 2.40$ & $2.94 \pm 2.32$ \\
Exercise & $5.95 \pm 8.22$ & $2.10 \pm 2.00$ & $2.12 \pm 2.05$ \\
\hline
\end{tabular}

Mean \pm Standard Deviation.

* \# Significant differences $(p<0.05)$ in comparison with other stimuli according to linear mixed-effects model.

with methacholine and exercise $(\mathrm{p}<0.01)$. There were no differences between exercise and methacholine $(\mathrm{p}=0.31)$. In terms of dyspnea measured by Borg scale, there were no differences among stimuli $(\mathrm{p} \geq 0.15)$. When dyspnea was measured by VAS, bradykinin induced more dyspnea than exercise $(\mathrm{p}=0.04)$ and than methacholine $(\mathrm{p}=0.02)$.

The baseline $\mathrm{FEV}_{1}$ had effect on cough (estimate 3.10; 95\% CI 0.77-5.43; p < 0.01) and on dyspnea evaluated by Borg scale (estimate $6.96 ; 95 \% \mathrm{CI} 2.95-10.96 ; \mathrm{p}<0.01$ ) or by VAS (estimate $5.08 ; 95 \%$ CI $0.89-9.26 ; \mathrm{p}=0.02$ ). These positive-estimate values indicate that higher baseline $\mathrm{FEV}_{1}$ leads to more symptoms during $\mathrm{FEV}_{1}$ fall. For the following covariables, no effect has been detected on cough or dyspnea: body mass index, atopy status, age, gender, tests sequence and inhaled corticosteroid dose.

\section{Discussion}

In this cross over study, 20 asthmatic subjects were evaluated. Self-reported ratings of the intensity of dyspnea (assessed by Borg and VAS) and coughing counts were made during bradykinin, methacholine and exercise induced bronchoconstriction. The study showed that bradykinin induced more cough and dyspnea than methacholine and exercise. As expected, dyspnea increased during challenge tests, so did cough. Some studies failed to show this dose-related increase in cough counts during bronchoconstriction $[15,16]$.

Our data support the proposal of using cough to evaluate bronchial responsiveness in special groups of patients. Technical difficulties in performing spirometry are common: one out of five elderly subjects cannot perform spirometry according to the international guidelines [17]. Similarly, approximately $30 \%$ of pre-school children are

Table 3: Pairwise comparisons according to linear mixed-effects model of modified Borg scale, visual analogue scale (VAS) and cough (logarithmic scale).

\begin{tabular}{|c|c|c|c|}
\hline \multicolumn{4}{|c|}{ Cough } \\
\hline Comparisons & Mean Difference* & $95 \% \mathrm{Cl}$ & $\mathrm{P}$-value \\
\hline Bradykinin $\times$ Exercise & 2.79 & $(1.83 ; 3.76)$ & $<0.01$ \\
\hline Bradykinin $\times$ Methacholine & 2.22 & $(1.12 ; 3.32)$ & $<0.01$ \\
\hline Exercise $\times$ Methacholine & -0.58 & $(-1.69 ; 0.53)$ & 0.31 \\
\hline \multicolumn{4}{|c|}{ Dyspnea - Borg } \\
\hline Comparisons & Mean Difference* & $95 \% \mathrm{Cl}$ & $\mathrm{P}$-value \\
\hline Bradykinin $\times$ Exercise & 1.20 & $(-0.4 I ; 2.8 I)$ & 0.15 \\
\hline Bradykinin $\times$ Methacholine & 0.59 & $(-1.23 ; 2.43)$ & 0.52 \\
\hline Exercise $\times$ Methacholine & -0.60 & $(-2.46 ; 1.25)$ & 0.52 \\
\hline \multicolumn{4}{|c|}{ Dyspnea - VAS } \\
\hline Comparisons & Mean Difference* & $95 \% \mathrm{Cl}$ & $\mathrm{P}$-value \\
\hline Bradykinin $\times$ Exercise & 1.76 & $(0.09 ; 3.42)$ & 0.04 \\
\hline Bradykinin $\times$ Methacholine & 2.28 & $(0.39 ; 4.18)$ & 0.02 \\
\hline Exercise $\times$ Methacholine & 0.53 & $(-1.39 ; 2.44)$ & 0.59 \\
\hline
\end{tabular}

$\mathrm{Cl}$ : confidence interval. *The model was adjusted by intercept, age, gender, atopy status, body mass index, $\mathrm{FEV}_{1}$, baseline $\mathrm{FEV}_{1}$, bradykinin, methacholine and exercise, baseline symptom, inhaled corticosteroid dose and tests sequence. 
unable to perform acceptable efforts [18]. In the evaluation of challenge induced cough, bradykinin would probably be the best stimulus because it could increase the sensitivity of the test by increasing cough intensity.

In addition, during challenge tests, cough and dyspnea were significantly more intense in subjects with higher baseline pulmonary function (baseline $\mathrm{FEV}_{1}$ ). Probably, patients with prolonged airflow obstruction would be less breathless for any given reduction in $\mathrm{FEV}_{1}$ than those with higher baseline $\mathrm{FEV}_{1}$, a process known as temporal adaptation [19]. This is in favor of the use of cough to define positive bronchial challenge test, given that most patients who need challenge tests are not severe enough to have very low $\mathrm{FEV}_{1}$.

Some theories are able to explain why, in patients with asthma, the severity of breathlessness is greater during bradykinin than methacholine or exercise challenge at given levels of airway obstruction: a) bradykinin challenge test causes more cough and this could interfere in dyspnea perception, increasing it; b) methacholine has $\mathrm{PC}_{20}$ lower than bradykinin and this could be associated with faster bronchospasm, shorter sensory duration of the experience; c) intensity of asthma symptoms depends on the mechanisms that are involved in the induction of airway obstruction [10]. The difference in mode of action among three stimuli should be considered potential determinant of breathlessness severity. For instance, after exercise, various sensations from physical discomfort could have influenced scoring of perceived breathlessness and it is not known what the effect of exercise itself is on cough or sensation of dyspnea. One solution to these potential problems could be a bronchial provocation challenge that would reproduce the hyperventilation of exercise, e.g. eucapnic voluntary hyperventilation of cold and dry air [20].

Another study has showed that bradykinin inhalation caused cough and retroesternal discomfort, but authors did not evaluate cough quantitatively [16]. In a more recent study with 12 subjects with mild asthma, authors recorded and counted coughs episodes. They showed that, in general, bradykinin induced more coughing than did methacholine, however, there were some subjects who rarely coughed to either stimuli, whereas others had a marked cough response regardless of the stimuli [15].

Despite cough is a very common symptom and the mechanisms contributing to it are widely studied, there has been much debate, for instance, surrounding the identity of the airway afferent nerve subtype that precipitates reflex coughing. Studies in experimental animals and in humans show clearly that multiple afferent nerve subtypes (mechanosensors and chemosensors) might be involved in the production of reflex coughing. However, not all stimuli evoke cough under all conditions. This might suggest divergence between multiple reflex pathways or the existence of primary and secondary cough afferent pathways [21]. Also, there is a suspicious that a complex allergic reaction in the airway may be involved in the development of antigen-induced increase in cough reflex sensitivity [22]. There is evidence of the involvement of airway vagal afferents, such as sensory C-fibers, and rapidly adapting receptors in the cough reflex, as well as in other symptoms of respiratory disease, such as bronchospasm $[23,24]$. Bradykinin, capsaicin and citric acid, stimuli that are known to active airway chemosensors, are amongst the most potent tussigenic agent in conscious animals and humans[21].

The mechanisms of tussive and bronchoconstrictor responses to bradykinin may be the same, via C-fibers [25]. The non-myelinated C-fibers contain the tachykinins substance $\mathrm{P}$, neurokinin $\mathrm{A}$ and neurokinin $\mathrm{B}$ which, upon release, act on NK1, NK2, NK3 receptors respectively to mediate several functions [26]. Whilst inhalation of citric acid stimulates both $\mathrm{C}$-fibers and rapidly adapting receptors, capsaicin appears to stimulate only C-fibers and both these agents have been shown to induce cough, in several species including man, and also bronchoconstriction [21,26-30].

In several studies, dyspnea score are usually plotted against percentage of fall in $\mathrm{FEV}_{1}$ and individual symptoms/ $\mathrm{FEV}_{1}$ ratios are used to represent an index of dyspnea, and their corresponding intercepts, representing baseline symptoms. These variables are calculated by linear regression analysis $[19,31]$. The mixed procedure fits a variety of mixed linear models to data and enables the use of these fitted models to make statistical inferences about the data. The linear mixed-effects models, therefore, provides flexibility of modeling not only the means of data (as in the standard linear model) but their variances and covariances as well [14].

Some studies make video recordings or employ simultaneous recordings of flow rate, air volume, subglottic pressure and acoustic signal to evaluate cough. However, the use of different devices could interfere with dyspnea sensation, plus, there is a recent study (comparing video recordings and audio recordings) showing that trained observers are able to achieve good agreement counting cough manually from audio recordings [32]. Another study showed that the agreement between simultaneous (at the same time when the test is being conducted) and video counting of coughs is generally good. To ensure reliable simultaneous cough counting, challenge tests should be performed in a quiet environment, applying as little 
unnecessary equipment and measurements as possible [33].

\section{Conclusion}

Bradykinin challenge provides the strongest coughing intensity and breathlessness for a given fall in $\mathrm{FEV}_{1}$, and is thereby recommended for protocols planned to evaluate cough. Bradykinin may act on neural mechanisms that modulate symptoms, increasing cough and dyspnea in asthmatic patients. These data corroborate previous studies that showed, in experimental models, a role for bradykinin in the mechanism of cough.

\section{List of abbreviations}

$\mathrm{FEV}_{1}$ : forced expiratory volume in one second; VAS: Visual Analogue Scale; $\mathrm{PC}_{20}$ : provocative concentration of any stimulus resulting in a $20 \%$ fall in $\mathrm{FEV}_{1}$; $\mathrm{BK}$ : bradykinin; MCh: methacholine; EIB: exercise-induced bronchospasm; NK: neurokinin.

\section{Competing interests}

The authors declare that they have no competing interests.

\section{Authors' contributions}

TRS recruited the subjects, performed the data collecting and draft the manuscript. EZM and CAG performed the statistical analysis and interpretation of data. EOV participated in conception, design of the study, coordination, helped to draft the manuscript and critical revision. All authors have given final approval of the version to be published.

\section{Acknowledgements}

This work was supported by grants from S. Paulo State Government (FAPESP - grants: 98/10382-6 and 03/09865-2). The authors would like to thank Elizabet Sobrani for her technical assistance and Eliza Omai for her assistance with the statistical analysis.

\section{References}

I. Koskela HO, Hyvarinen L, Brannan JD, Chan HK, Anderson SD: Coughing during mannitol challenge is associated with asthma. Chest 2004, I 25:1985-1992.

2. Koskela HO, Kontra KM, Purokivi MK, Randell JT: Interpretation of cough provoked by airway challenges. Chest 2005, I 28:3329-3335.

3. Koskela HO, Martens R, Brannan JD, Anderson SD, Leuppi J, Chan HK: Dissociation in the effect of nedocromil on mannitolinduced cough or bronchoconstriction in asthmatic subjects. Respirology 2005, 10:442-448.

4. Sheppard D, Rizk NW, Boushey HA, Bethel RA: Mechanism of cough and bronchoconstriction induced by distilled water aerosol. Am Rev Respir Dis 1983, I 27:691-694.

5. Van Schoor J, Joos GF, Pauwels RA: Indirect bronchial hyperresponsiveness in asthma: mechanisms, pharmacology and implications for clinical research. Eur Respir ] 2000, I 6:5 | 4-533.

6. National Institutes of Health: Global strategy for asthma management and prevention: global iniciative for asthma (GINA). Bethesda: National Heart, Lung and Blood Institute Publication; 2002:02.

7. Yanagihara N, Von Leden H, Werner-Kukuk E: The physical parameters of cough: the larynx in a normal single cough. Acta Otolaryngol 1966, 6 I:495-510.
8. Wilson RC, Jones PW: A comparison of the visual analogue scale and modified Borg scale for the measurement of dyspnoea during exercise. Clin Sci (Lond) 1989, 76:277-282.

9. Noseda A, Schmerber J, Prigogine T, Yernault JC: Perceived effect on shortness of breath of an acute inhalation of saline or terbutaline: variability and sensitivity of a visual analogue scale in patients with asthma or COPD. Eur Respir J 1992, 5:1043-1053.

10. Sont JK, Booms P, Bel EH, Vandenbroucke JP, Sterk PJ: The severity of breathlessness during challenges with inhaled methacholine and hypertonic saline in atopic asthmatic subjects. The relationship with deep breath-induced bronchodilation. Am J Respir Crit Care Med 1995, I 52:38-44.

II. Crapo RO, Casaburi R, Coates AL, Enright PL, Hankinson JL, Irvin CG, Maclntyre NR, McKay RT, Wanger JS, Anderson SD, Cockcroft DW, Fish JE, Sterk PJ: Guidelines for methacholine and exercise challenge testing- 1999. This official statement of the American Thoracic Society was adopted by the ATS Board of Directors, July 1999. Am J Respir Crit Care Med 2000, I 6 I :309-329.

12. Vianna EO, Boaventura LC, Terra-Filho J, Nakama GY, Martinez JA, Martin RJ: Morning-to-evening variation in exercise-induced bronchospasm. J Allergy Clin Immunol 2002, I I 0:236-240.

13. Schall R: Estimation in generalized linear models with random effects. Biometrika 1991, 78:719-727.

14. Little RC, Milliken GA, Stroup WW, Wolfinger RD: SAS System for mixed models. Cary, NC: SAS Institute Inc; 1996.

15. Berman AR, Togias AG, Skloot G, Proud D: Allergen-induced hyperresponsiveness to bradykinin is more pronounced than that to methacholine. J Appl Physiol 1995, 78: |844- I852.

16. Fuller RW, Dixon CM, Cuss FM, Barnes PJ: Bradykinin-induced bronchoconstriction in humans. Mode of action. Am Rev Respir Dis 1987, 135:176-180.

17. Pezzoli L, Giardini G, Consonni S, Dallera I, Bilotta C, Ferrario G, Sandrini MC, Annoni G, Vergani C: Quality of spirometric performance in older people. Age Ageing 2003, 32:43-46.

18. Dundas I, Mckenzie S: Spirometry in the diagnosis of asthma in children. Curr Opin Pulm Med 2006, I 2:28-33.

19. Burdon JG, Juniper EF, Killian KJ, Hargreave FE, Campbell EJ: The perception of breathlessness in asthma. Am Rev Respir Dis 1982, I 26:825-828.

20. Phillips YY, Jaeger JJ, Laube BL, Rosenthal RR: Eucapnic voluntary hyperventilation of compressed gas mixture. A simple system for bronchial challenge by respiratory heat loss. Am Rev Respir Dis 1985, I 3 I:31-35.

21. Mazzone SB: An overview of the sensory receptors regulating cough. Cough 2005, I:2.

22. Hara J, Fujimura M, Myou S, Oribe Y, Furusho S, Kita T, Katayama N, Abo M, Ohkura N, Herai Y, Hori A, Ishiura Y, Nobata K, Ogawa H, Yasui M, Kasahara K, Nakao S: Comparison of cough reflex sensitivity after an inhaled antigen challenge between actively and passively sensitized guinea pigs. Cough 2005, I:6.

23. Adcock J): Mechanism of cough. In Drugs for the tratment of respiratory diseases Edited by: Domenico S, et al. Cambridge, UK: Cambridge University Press; 2003:553-564.

24. El Hashim AZ, Amine SA: The role of substance $\mathbf{P}$ and bradykinin in the cough reflex and bronchoconstriction in guineapigs. Eur J Pharmacol 2005, 5 I 3: I 25- I 33.

25. Tatar M, Webber SE, Widdicombe JG: Lung C-fibre receptor activation and defensive reflexes in anaesthetized cats. J Physiol 1988, 402:4 I I-420.

26. El Hashim AZ, Wyss D, Lewis C: Effect of a novel NKI receptor selective antagonist (NKP608) on citric acid induced cough and airway obstruction. Pulm Pharmacol Ther 2004, I 7: I I- I8.

27. Kondo T, Kobayashi I, Hayama N, Ohta Y: An increase in the threshold of citric acid-induced cough during chest wall vibration in healthy humans. Jpn J Physiol 1998, 48:34I-345.

28. Lalloo UG, Fox AJ, Belvisi MG, Chung KF, Barnes PJ: Capsazepine inhibits cough induced by capsaicin and citric acid but not by hypertonic saline in guinea pigs. J Appl Physiol 1995, 79: $1082-1087$.

29. Undem BJ, Carr MJ, Kollarik M: Physiology and plasticity of putative cough fibres in the Guinea pig. Pulm Pharmacol Ther 2002, I5:193-198.

30. Yasumitsu R, Hirayama Y, Imai T, Miyayasu K, Hiroi J: Effects of specific tachykinin receptor antagonists on citric acid-induced 
cough and bronchoconstriction in unanesthetized guinea pigs. Eur J Pharmacol 1996, 300:215-219.

31. Kendrick AH, Higgs CM, Whitfield MJ, Laszlo G: Accuracy of perception of severity of asthma: patients treated in general practice. BMJ 1993, 307:422-424.

32. Smith JA, Earis JE, Woodcock AA: Establishing a gold standard for manual cough counting: video versus digital audio recordings. Cough 2006, 2:6.

33. Koskela HO, Purokivi MK, Tukiainen RM: Simultaneous versus video counting of coughs in hypertonic cough challenges. Cough 2008, 4:8.

Publish with Biomed Central and every scientist can read your work free of charge

"BioMed Central will be the most significant development for disseminating the results of biomedical research in our lifetime. " Sir Paul Nurse, Cancer Research UK

Your research papers will be:

- available free of charge to the entire biomedical community

- peer reviewed and published immediately upon acceptance

- cited in PubMed and archived on PubMed Central

- yours - you keep the copyright

Submit your manuscript here:

http://www.biomedcentral.com/info/publishing_adv.asp 